\title{
A Novel Crystallization Scheme in Poly[styrene-block-(ferrocenyl dimethylsilane)] Diblock Copolymers
}

\author{
Jianjun Xu, Vasilios Bellas, Bernd Jungnickel, Bernd Stühn, \\ Matthias Rehahn*
}

Isothermal crystallization of the poly(ferrocenyl dimethylsilane) (PFDMS) segments in a poly[styrene-block-(ferrocenyl dimethylsilane)] (PS-b-PFDMS) diblock copolymer of lamellar micro-morphology has been investigated. The PFDMS is shown to crystallize in a confined and grain-by-grain fashion. Here a 'grain' is defined as an ensemble of stacked lamellae wherein the PFDMS crystallization spreads quickly but stops at its surroundings. Such crystallization propagates not only along the PFDMS lamellae but across the amorphous PS layers as well. We suggest that conformational changes in the PS as induced by the PFDMS crystallization ('squeezing transfer') are responsible for the latter pathway of the crystallization's spread.

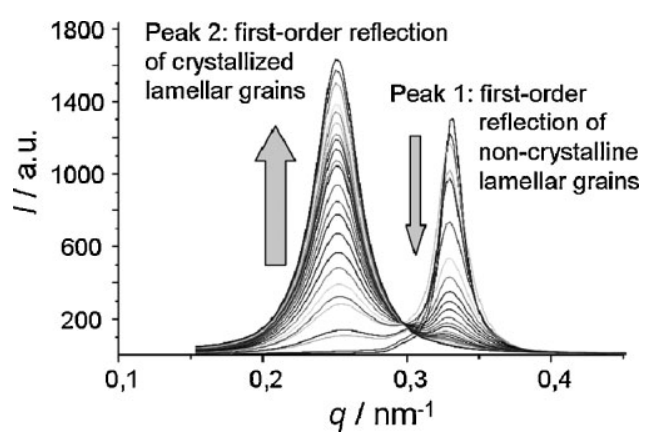

\section{Introduction}

Block copolymers containing crystallizing segments provide a deep insight into the mechanisms of nucleation and crystal growth. ${ }^{[1-27]}$ Ouite often, the number of individually crystallizing entities such as spheres, cylinders, or lamellae is much larger than the overall number of heterogeneities inside the samples. In such cases, fractionated crystallization or crystallization induced by homogeneous nuclea-

J. Xu, V. Bellas, M. Rehahn

Ernst-Berl-Institut für Technische und Makromolekulare Chemie, Technische Universität Darmstadt, 64287 Darmstadt, Germany E-mail: Mrehahn@dki.tu-darmstadt.de B. Jungnickel, B. Stühn Institut für Festkörperphysik, Technische Universität Darmstadt, 64289 Darmstadt, Germany

J. Xu, B. Jungnickel, M. Rehahn

Deutsches Kunststoff-Institut (DKI), 64289 Darmstadt,

Germany tion may be the consequence. Moreover, microphasesegregated block copolymers allow the study of crystallization under confined conditions, leading to unusual crystalline structures. The impact of the confinements on initiation, progress, and result of crystallization can be analyzed systematically. The length scales of the confinements can be tailored conveniently from below ten nanometers up to several hundreds of nanometers by appropriately adjusting the lengths of the respective blocks or by blending the block copolymers with the corresponding homopolymers. Furthermore, the confinements' dimensionality (e.g., 1D for lamellae, 2D for cylinders, and 3D for spheres) can be tailored by adjusting the volume fractions of the respective sub-phases. Plenty of fascinating observations have been made, but even more questions are awaiting a detailed analysis.

Most of the crystallizing block copolymers investigated so far contain either polyethylene or poly(ethylene oxide) (PEO) as crystallizable segments. For complementary studies, moreover, block copolymers would be highly 
valuable which are composed of a non-crystallizing A-block and a crystallizing B-block where i) both blocks have their glass transition temperatures $\left(T_{\mathrm{g}} \mathrm{s}\right)$ below the crystallization temperature $\left(T_{\mathrm{c}}\right)$ of the crystallizing one, ii) the B-block only shows moderate rates of nucleation and crystal growth, and iii) the copolymer allows highresolution transmission electron microscopy (TEM) and $\mathrm{X}$-ray scattering measurements without staining and thus in-situ monitoring of B-block crystallization. Poly(ferrocenyl dimethylsilane) (PFDMS) ${ }^{[28-39]}$ might act as such a novel crystallizing B-block system: PFDMS has already attracted much attention as a result of its (opto)electronic and redox properties, because it can be converted into ceramic and magnetic materials, and because it is available by living anionic polymerization which provides access to plenty of well-defined copolymer architectures. ${ }^{[34-54]}$ Another special feature of PFDMS is its low rate of nucleation and crystal growth. Even determination of the equilibrium melting temperature, $T_{\mathrm{m}, 0}$, has, therefore, been a challenge: using the linear Hoffmann-Weeks (HW) approach, ${ }^{[1,24,55,56]}$ a $T_{\mathrm{m}, 0}$ of $144^{\circ} \mathrm{C}$ was obtained, ${ }^{[30,31,57]}$ but following the GibbsThomson (GT) procedure, ${ }^{[1,24,58]}$ a $T_{\mathrm{m}, 0}$ of $215^{\circ} \mathrm{C}$ was the result. ${ }^{[57]}$ Moreover, a $T_{m, 0}$ of $179^{\circ} \mathrm{C}$ was determined when the melting of PFDMS as part of a phase-separated PS- $b$ PFDMS diblock copolymer (PS: polystyrene) of lamellar micro-morphology was addressed. ${ }^{[57]}$ Since understanding the quite special PFDMS crystallization characteristics could significantly contribute to a well-grounded knowledge of crystallization in phase-separated block copolymers in general, we started a profound analysis of PS- $b$-PFDMS systems. This paper focuses on the isothermal crystallization of lamellar PFDMS microphases and results in the suggestion of a novel type of crystallization in block copolymers.

It is widely assumed that lamellar block copolymers crystallize like a percolating system where the percolating entities may be structural defects of any kind in the lamellar structure. ${ }^{[59-63]}$ This may hold even in strongly segregated block copolymers and leads to a crystallization kinetics which is similar to that of homopolymers. The defects then act as secondary nuclei. Such a crystallization path will cause a homogeneous spread of crystallization throughout the whole material whatever the actual percolating entities are and the percolating paths look like. It will be shown that the system under investigation here deviates from such a process in a manner where fully crystallized 'grains' coexist with still fully amorphous ones, and that crystallization is consequently inhomogeneous on a microscopic level. Moreover, crystallization in such a grain unusually proceeds rapidly. We believe that this crystallization scheme cannot be understood in the frame of the existing ones. It is one of the aims of the present paper to provide an explanation of that behavior which to our knowledge has not been reported so far.

\section{Experimental Part}

\section{Materials}

The PS- $b$-PFDMS diblock copolymer under investigation here (Figure 1) was prepared by sequential living anionic polymerization as described recently. ${ }^{[57]}$ Its overall molar mass $\left(\bar{M}_{n}\right)$ was $24.3 \mathrm{~kg} \cdot \mathrm{mol}^{-1}$ (polydispersity index (PDI) $=1.05$ ). The PS block had a $\bar{M}_{\mathrm{n}}$ of $12.0 \mathrm{~kg} \cdot \mathrm{mol}^{-1}$, and the $\bar{M}_{\mathrm{n}}$ of the PFDMS block was $12.3 \mathrm{~kg} \cdot \mathrm{mol}^{-1}$. At room temperature, the volume fraction of PS in the amorphous and crystalline samples was 0.586 and 0.614 , respectively, assuming a density of $1.05 \mathrm{~g} \cdot \mathrm{cm}^{-3}$ for the amorphous PS and densities of 1.294 and $1.455 \mathrm{~g} \cdot \mathrm{cm}^{-3}$ for the amorphous and crystalline PFDMS, respectively. ${ }^{[30-32]}$ The composition results in a lamellar micro-morphology at all temperatures below the orderdisorder transition (ODT).

As PFDMS crystallizes very slowly, the self-seeding technique $^{[1,57,64-73]}$ was applied to ensure PFDMS crystallization in experimentally acceptable periods of time. The required precrystallized samples were obtained by first heating the powdery 'as-synthesized' PS- $b$-PFDMS to $180^{\circ} \mathrm{C}$ for 60 min in order to destroy any kind of preformed crystalline order. Subsequently, the molten material was pressed at $145^{\circ} \mathrm{C}$ between two parallel steel plates to films of $0.3 \mathrm{~mm}$ thickness, and then annealed at $180^{\circ} \mathrm{C}$ for $10 \mathrm{~min}$ for homogenization, and finally allowed to crystallize at $T_{\mathrm{c}}=127^{\circ} \mathrm{C}$ for approx. $60 \mathrm{~h}$. Just prior to the crystallization study, the precrystallized sample was carefully heated $\left(1 \mathrm{~K} \cdot \mathrm{min}^{-1}\right)$ to $147^{\circ} \mathrm{C}$, i.e., to a temperature slightly above $T_{\mathrm{m}}$ (PFDMS). After keeping the sample at that temperature for 1-2 min, it was quenched at $20 \mathrm{~K} \cdot \mathrm{min}^{-1}$ to the desired $T_{\mathrm{c}}$ of the crystallization experiment. The intermediate short-term annealing at $147^{\circ} \mathrm{C}$ results in the disappearance of the crystalline order to an extent that the PFDMS appears amorphous from the macroscopic point of view: crystalline regions cannot be detected any more, neither by calorimetry, nor by nuclear magnetic resonance, nor by microscopic techniques. Nevertheless, some structural entities survive this procedure and considerably support nucleation when the material is subsequently cooled down to $T_{\mathrm{c}}$. It is still a matter of controversy whether some local chain orientation or even tiny crystallites survive the intermediate melting. In addition, self-seeded crystallization might profit from improved microphase segregation since, upon PFDMS crystallization, the block copolymer changes from the weak into the strong segregation regime. ${ }^{[75]}$ It is reasonable to assume that precrystallization results in microphases that are more completely demixed, and the short-term melting of the pre-crystallized material is certainly not long enough to cause significant remixing of the chain segments. Moreover, in preceding studies, ${ }^{[57]}$ we could verify that self-seeding lowers the nucleation barrier but

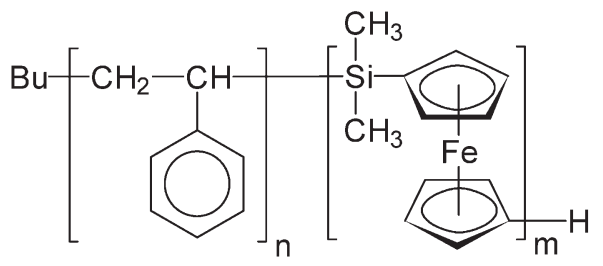

Figure 1. Chemical formula of the PS- $b$-PFDMS diblock polymer under investigation. 
does not change the crystallization behavior of PFDMS in any other respect.

\section{Methods}

Differential scanning calorimetry (DSC) was carried out under an atmosphere of nitrogen using a Perkin-Elmer DSC 7 instrument. Small angle and wide angle X-ray scattering (SAXS and WAXS) measurements were carried out at the synchrotron radiation beamline A2 in HASYLAB, DESY, Hamburg, at a wavelength of $0.15 \mathrm{~nm}$. Two-dimensional SAXS data and 1D WAXS data were recorded. The 2D images were circularly integrated using the Fit2D program ${ }^{[74]}$ after normalization by the ionization intensity and subtraction of the background scattering caused by air and the sample holder. TEM was carried out using a Zeiss CEM 902 electron microscope operating at $80 \mathrm{kV}$ on samples cut at $-70{ }^{\circ} \mathrm{C}$ into $50 \mathrm{~nm}$ slices using a diamond knife. All images were recorded with a SlowScan CCD camera from ProScan Inc. in bright-field mode. Computeraided camera control was achieved using the Vario Vision software 3.2 from LEO.

\section{Results and Discussion}

At all temperatures below the ODT, which is at $207^{\circ} \mathrm{C}$ for the PS- $b$-PFDMS diblock copolymer investigated here, ${ }^{[75,76]}$ the bulk morphology of the fully non-crystalline ('amorphous') material was lamellar. This could be verified best by TEM of the samples which were heated to $180^{\circ} \mathrm{C}$ for $10 \mathrm{~min}$, annealed at $150^{\circ} \mathrm{C}$ for $1 \mathrm{~h}$, and finally quenched to room temperature (Figure $2 \mathrm{a}$ ). This annealing procedure allows an efficient approach to the equilibrium microphase structure which is characterized by stacks of amorphous lamellae. On the other hand, it does not yet reliably induce PFDMS crystallization: no PFDMS crystallization was observed even after annealing at temperatures of up to $130{ }^{\circ} \mathrm{C}$ for $1 \mathrm{~d}$. Therefore, it was not a difficult task to characterize the microphase-separated but still fully

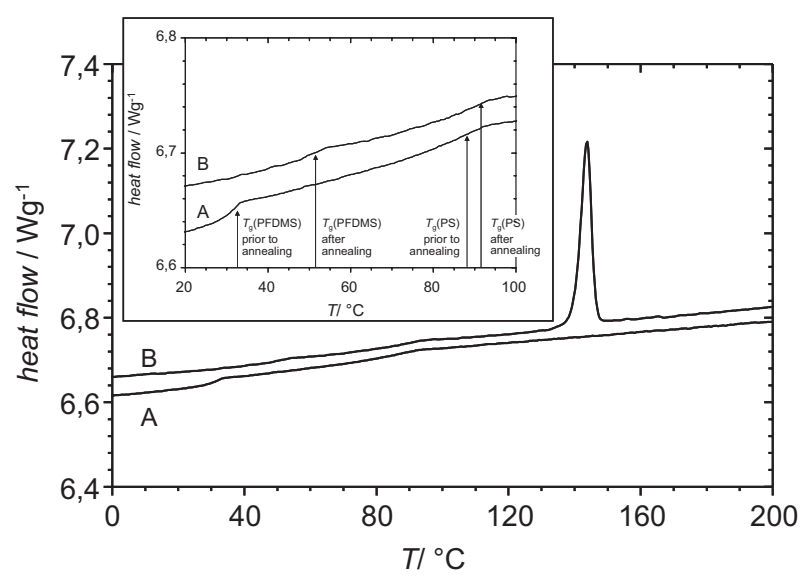

Figure 3. DSC heating runs (heating rate: $10 \mathrm{~K} \cdot \mathrm{min}^{-1}$ ) of PS- $b$ PFDMS samples having different thermal histories; A: after cooling from 180 to $5^{\circ} \mathrm{C}$ at $0.5 \mathrm{~K} \cdot \mathrm{min}^{-1}$; B: after annealing at $127^{\circ} \mathrm{C}$ for $64 \mathrm{~h}$. The insert indicates the glass transition temperatures (heat flow jumps) of the block components for the cases $A$ and $B$.

amorphous material in a broad range of temperatures using SAXS (Figure 2b). The first-order and third-order scattering peaks of the lamellar micro-morphology appear throughout, whereas the second-order peaks were suppressed because of coincidence with the structure factor's minimum.

The non-crystalline block copolymer was also characterized using DSC and WAXS. No melting endotherms were found in the DSC heating runs of samples, which were first cooled from $180^{\circ} \mathrm{C}$ to room temperature with cooling rates from 0.5 to $30 \mathrm{~K} \cdot \mathrm{min}^{-1}$ (Figure 3 , curve A). Two glass transitions appear instead, which correspond to the PS-rich and the PFDMS-rich microphases, respectively: $T_{\mathrm{g}}$ (PFDMS) was at $31^{\circ} \mathrm{C}$, and $T_{\mathrm{g}}(\mathrm{PS})$ was at $87.5^{\circ} \mathrm{C}$. The latter value is slightly below that of a PS homopolymer having identical molar mass $\left(93.4^{\circ} \mathrm{C}\right)$. Obviously, some PFDMS resides in the PS-rich microphases and acts there as a softening agent.
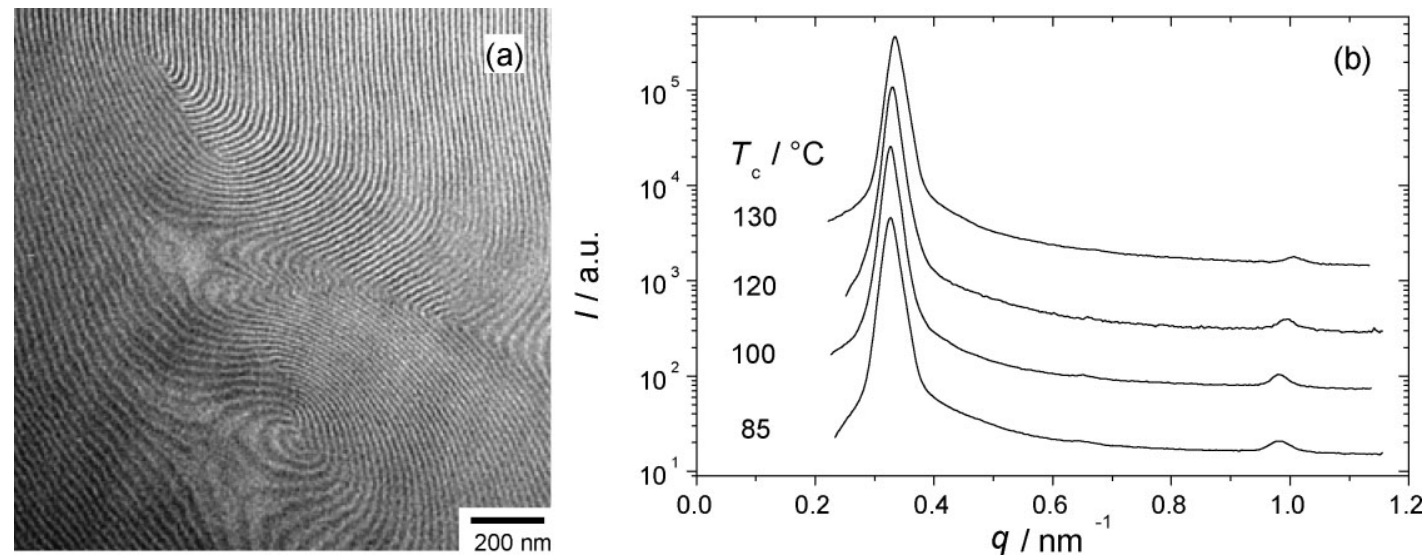

Figure 2. a) TEM image of a microphase-separated but non-crystalline PS- $b$-PFDMS sample measured at room temperature. b) SAXS curves of microphase-separated but still amorphous PS- $b$-PFDMS, measured at different temperatures (curves are shifted arbitrarily for clarity). 

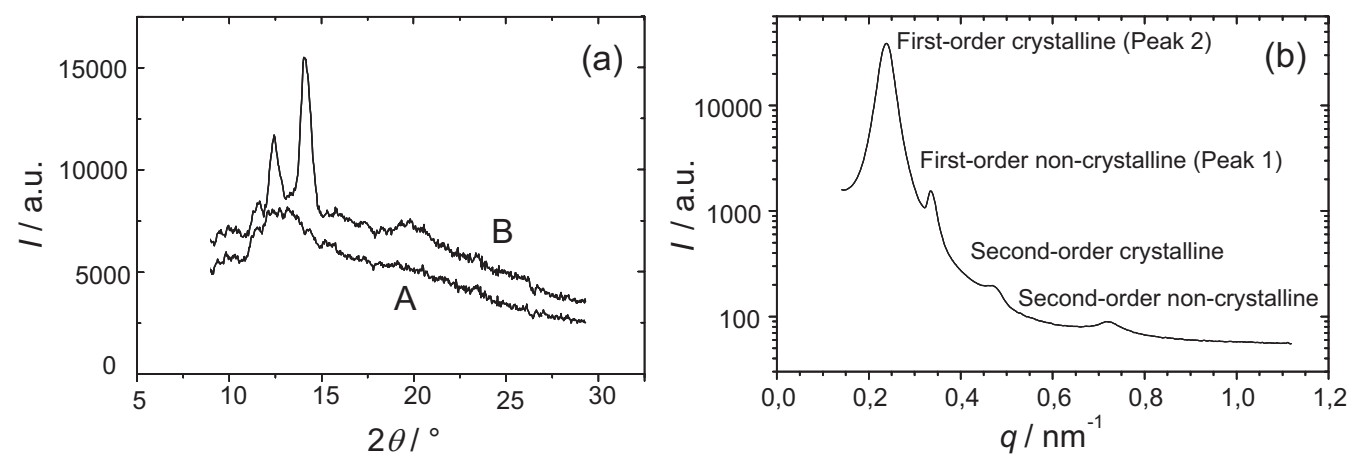

Figure 4. a) WAXS patterns (recorded at $30^{\circ} \mathrm{C}$ ) of PS-b-PFDMS samples having different thermal histories; A: after cooling from 180 to $5^{\circ} \mathrm{C}$ at $0.5 \mathrm{~K} \cdot \mathrm{min}^{-1}$; B: after annealing at $127^{\circ} \mathrm{C}$ for $64 \mathrm{~h}$. b) SAXS curve of a PS- $b$-PFDMS sample after incomplete crystallization at $127^{\circ} \mathrm{C}$ for $64 \mathrm{~h}$.

This is in agreement with the fact that, under the given conditions, the amorphous (non-crystalline) block copolymer is in the weak segregation regime of the phase diagram and, thus, PS and amorphous PFDMS are partially miscible. ${ }^{[57,75,76]}$ Vice versa, some PS appears to reside in the PFDMS lamellae: the observed $T_{\mathrm{g}}$ (PFDMS) is slightly above the $T_{\mathrm{g}}\left(27^{\circ} \mathrm{C}\right)$ of PFDMS homopolymers of comparable mass. Last but not least, the WAXS pattern (Figure $4 \mathrm{a}$, curve A) shows only the amorphous halo, and there are almost no indications of the future crystalline reflections.

Crystallization of PFDMS segments in the diblock copolymer was only observed if annealing was extended over very long periods of time: DSC and WAXS patterns recorded after annealing at $127^{\circ} \mathrm{C}$ for more than $60 \mathrm{~h}$ show an intense melting endotherm in the DSC run at $T_{\mathrm{m}} \approx 145^{\circ} \mathrm{C}$, and two sharp peaks in the WAXS at $2 \theta=12.4^{\circ}$ and $2 \theta=14.1^{\circ}$ (Figure 3 and $4 \mathrm{a}$; curves B). The WAXS peaks coincide with the 200 and 010 reflections found in melt-crystallized PFDMS homopolymers, ${ }^{\text {[30-32] }}$ and the DSC curves of the semi-crystalline sample gave $T_{\mathrm{g}}(\mathrm{PS})=89.5$ and $T_{\mathrm{g}}(\mathrm{PFDMS})=51^{\circ} \mathrm{C}$. The slight increase in $T_{\mathrm{g}}(\mathrm{PS})$ upon PFDMS crystallization is presumably attributable to the previously mentioned PS phase purification, i.e., release of PFDMS segments. The significant increase in $T_{\mathrm{g}}$ (PFDMS), on the other hand, is more difficult to explain. This will be addressed later in more detail.

Figure $4 b$ shows the SAXS curve of a PS- $b$-PFDMS sample that was annealed at $T_{\mathrm{C}}=127^{\circ} \mathrm{C}$ for $64 \mathrm{~h}$. The observed scattering pattern is representative of all block copolymer samples partially crystallized by annealing at temperatures in the range $30^{\circ} \mathrm{C} \leq T_{\mathrm{C}} \leq 140{ }^{\circ} \mathrm{C} .{ }^{[57]}$ Rather surprisingly, four clearly discernible scattering maxima are now resolved which obviously correspond to two different series of lamellar reflections.

If crystallization occurred in the PFDMS lamellae truly randomly, only the first-order SAXS reflection of Figure $2 b$ should appear, which should, however, shift progressively with increasing degree of crystallinity, corresponding to the progressive change in the average lamella long period, $L$, in the crystallizing system, and reflecting the associated change in density. Moreover, higher-order scattering peaks must not appear because of the lack of appropriate periodicity. Instead, only the width of the shifting peak should change systematically with changing degree of crystallinity. However, the PS- $b$-PFDMS sample investigated here did not follow this trend whatsoever. Instead, two well-resolved first-order reflections appear, both of them accompanied by their higher-order peaks. The only reasonable explanation of this feature is that two types of spatially well-separated lamella systems coexist in the crystallizing material. The first one contains stacks of noncrystalline PFDMS lamellae and has $L=18.7 \mathrm{~nm}$ (as known from Figure $2 b$ ), and the second one must then contain the crystallized PFDMS lamellae and has $L=26 \mathrm{~nm}$. Thus, the block copolymer must be sub-organized into grain-like assemblies, and each grain must contain ensembles of stacked lamellae. It must be separated from the surrounding grains in a fashion that crystallization in one grain does not induce crystallization in the others. ${ }^{a}$ Coexistence of amorphous and crystalline 'grains' is also reflected in some TEM pictures of incompletely crystallized samples (Figure 5), where two different sets of lamellar bundles can be seen, in clear contrast to our observations in the fully amorphous material.

Stimulated by such unexpected observations, timeresolved in-situ monitoring of the crystallization process was attempted using synchrotron SAXS. Advantage could be taken here of the considerable electron density provided by the iron centers of the PFDMS block, which allowed investigation of the material even using short-term measurements without staining. The samples used for the in-situ SAXS studies were again prepared following the

\footnotetext{
${ }^{a}$ Multiple domain structure is a well-known phenomenon in block copolymers. ${ }^{[77]}$ Nevertheless, we purposely differentiate the terms 'grain' and 'domain' because it is not clear whether the 'grains' being in operation in the context of PFDMS crystallization are identical to those usually called block-copolymer 'domains'.
} 


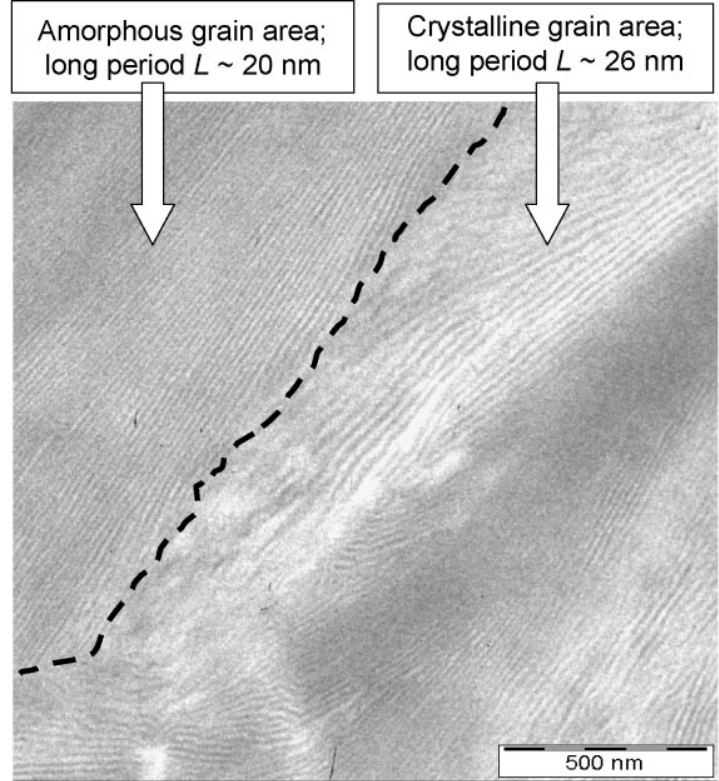

Figure 5. TEM image of a PS- $b$-PFDMS diblock copolymer after isothermal crystallization at $127^{\circ} \mathrm{C}$ for $64 \mathrm{~h}$, suggesting the coexistence of amorphous and crystalline grains. The dotted line indicates a grain boundary.

self-seeding technique. ${ }^{\mathrm{b}}$ The optimum range of temperatures for in situ monitoring of the isothermal self-seeded PFDMS crystallization was $80^{\circ} \mathrm{C} \leq T_{\mathrm{c}} \leq 140^{\circ} \mathrm{C},{ }^{[57]}$ which bridges the conditions from slightly below $T_{\mathrm{g}}(\mathrm{PS})$ up to clearly above $T_{\mathrm{g}}(\mathrm{PS})$. Figure 6a shows the first-order SAXS peaks recorded during an in situ study performed at $T_{\mathrm{C}}=110^{\circ} \mathrm{C}$

The features observed here are the same as those found at all other crystallization temperatures $T_{\mathrm{c}} \leq 125^{\circ} \mathrm{C}$ : peak 1 corresponds to the amorphous lamellar micro-morphology of the grains which are not yet crystallized. As soon as PFDMS crystallization starts, a second peak ('peak 2') appears at lower values of $q$. Increasing degrees of PFDMS crystallinity lead to the growth of peak 2 and, simultaneously, to decreasing intensities of peak 1 (Figure 6b). Finally, in the case of self-seeded samples, peak 1 vanishes completely, indicating essentially quantitative PFDMS crystallization. The most noticeable feature observed in the experiments carried out at $80^{\circ} \mathrm{C} \leq T_{\mathrm{c}} \leq 125^{\circ} \mathrm{C}$, however, was that the values of $q_{\max }$ remained almost unchanged for peak 1 as well as for peak 2 during the whole PFDMS crystallization process, which also supports the aforemen-

\footnotetext{
${ }^{\mathrm{b}}$ Qualitatively the same development of the scattering curves was found without self-seeding, i.e., when the PS- $b$-PFDMS was heated to $180^{\circ} \mathrm{C}$ immediately prior to the study. In those cases, however, crystallization was very slow and the experiment was extremely time-consuming.
}

tioned hypothesis of grain-by-grain crystallization. Obviously, full crystallization of all PFDMS lamellae within a grain proceeds so quickly that its kinetics cannot be resolved by the in situ SAXS technique and, hence, no intermediate stages of semi-crystallized grains contribute to the scattering curves.

If $T_{\mathrm{c}} \geq 130^{\circ} \mathrm{C}$, on the other hand, the crystallization behavior changes (Figure 7). Again, peak 1 corresponding to the non-crystalline grains disappears gradually, and a new peak 2 grows accordingly with proceeding PFDMS crystallization (Figure $7 \mathrm{a}, \mathrm{b}$ ). Now, however, only $q_{\max }$ of the developing peak 2 is nearly independent of the degree of crystallinity, while peak 1 shifts continuously toward lower values of $q$ (Figure 7c). Furthermore, peak 2 becomes much broader, and even peak 1 broadens slightly with increasing overall degree of PFDMS crystallinity. Last but not least, crystallization at $T_{\mathrm{c}} \geq 130^{\circ} \mathrm{C}$ was significantly slower than at lower $T_{\mathrm{C}} \mathrm{S}$ - despite self-seeding. At $130^{\circ} \mathrm{C}$, for example, complete PFDMS crystallization needed approx. $8 \mathrm{~h}$, but the same state was already reached after $4 \mathrm{~h}$ for $T_{\mathrm{c}}=110^{\circ} \mathrm{C}$.

Progressive broadening of peak 1 and the gradual shift of its $q_{\max }$ toward lower values for crystallization at $T_{\mathrm{C}} \geq 130^{\circ} \mathrm{C}$ indicates increasing lamella long periods, $L$, and thus a stretching normal to the lamella plane in grains that obviously still contain non-crystalline PFDMS. Thus, rapid grain-by-grain crystallization no longer occurs at those elevated temperatures, but crystallization is sufficiently retarded to allow resolution of the crystallization kinetics within the individual grains. Moreover, even after completed PFDMS crystallization, a lower degree of internal order is left, i.e., a broader distribution of lamella long periods, $L$, as is reflected by the clearly broadened peak 2 .

All in all, the in situ SAXS studies support our initial assumption that the PFDMS in the PS- $b$-PFDMS diblock copolymer crystallizes in a grain-by-grain fashion: bundles of originally non-crystalline PFDMS layers convert, in a closely coupled fashion, into their crystallized counterparts. This scenario proceeds at lower $T_{\mathrm{C}} \mathrm{S}$ so quickly that only the superposition of scattering curves of PS- $b$-PFDMS grains with either fully amorphous or fully crystallized PFDMS lamellae is displayed in the SAXS experiments. At higher $T_{\mathrm{C}} \mathrm{S}$, on the other hand, contributions of partially crystallized grains are also resolved. This agrees with the usual finding that the crystallization rate is lowered with increasing temperature.

The next issue was to analyze why PFDMS crystallization, once nucleated somewhere in a grain, spreads so quickly over so many lamellae. It is reasonable to assume that there is an efficient pathway accessible that allows the crystallization process to 'jump' from one lamella to the next, i.e., to pass through the amorphous PS layers. Screw dislocations and edge dislocations might act as carriers, as has already been discussed in the literature for thin films of poly(ethylene oxide-block-1,4-butadiene): using interference 

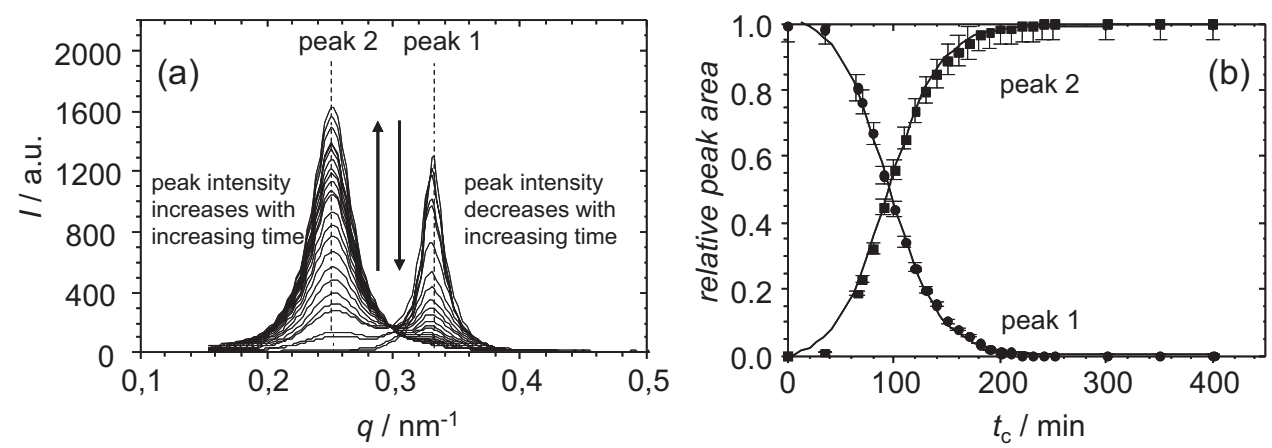

Figure 6. a) Time-resolved SAXS curves obtained during isothermal crystallization of the PFDMS domains at $T_{\mathrm{c}}=110^{\circ} \mathrm{C}$ (first-order peaks after subtraction of the background). Peak 1 corresponds to lamellar grains containing non-crystallized PFDMS segments, peak 2 to those containing crystallized PFDMS. b) Plot of the development of the relative areas of peak 1 and 2 of (a) vs. crystallization time, $t_{c}$.
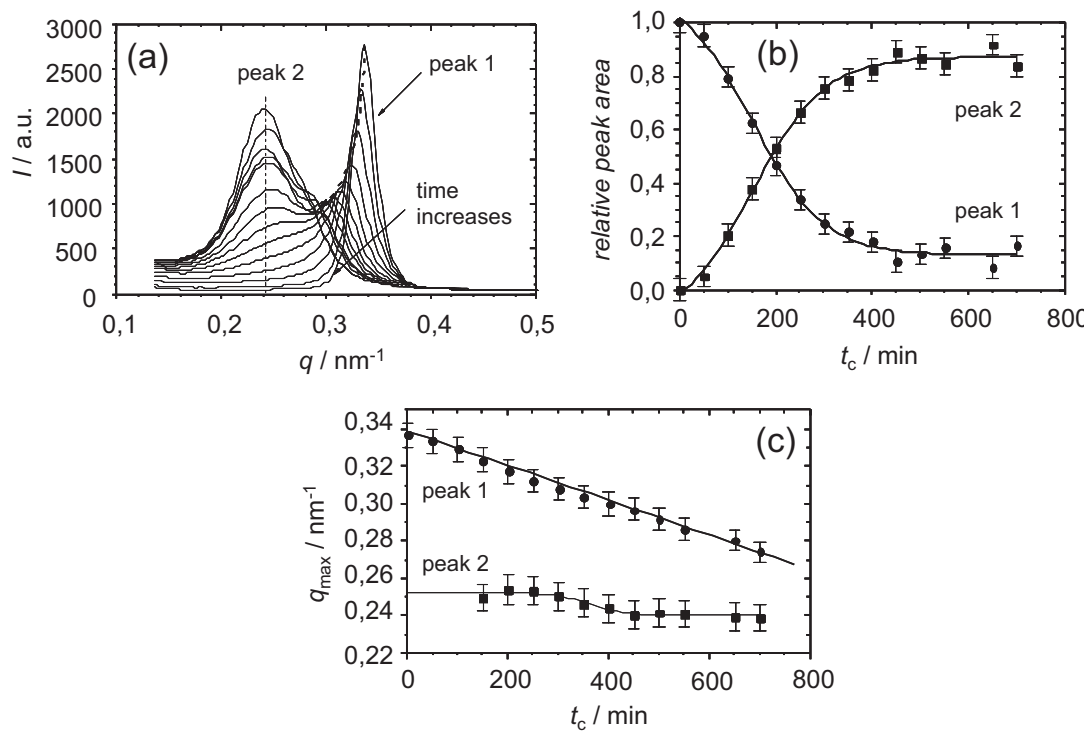

Figure 7. a) Time-resolved SAXS curves obtained during isothermal PFDMS crystallization at $130^{\circ} \mathrm{C}$. b) Plot of the respective relative peak areas vs. time (i.e., increase in crystallinity). c) Plot of the respective peak positions vs. time.
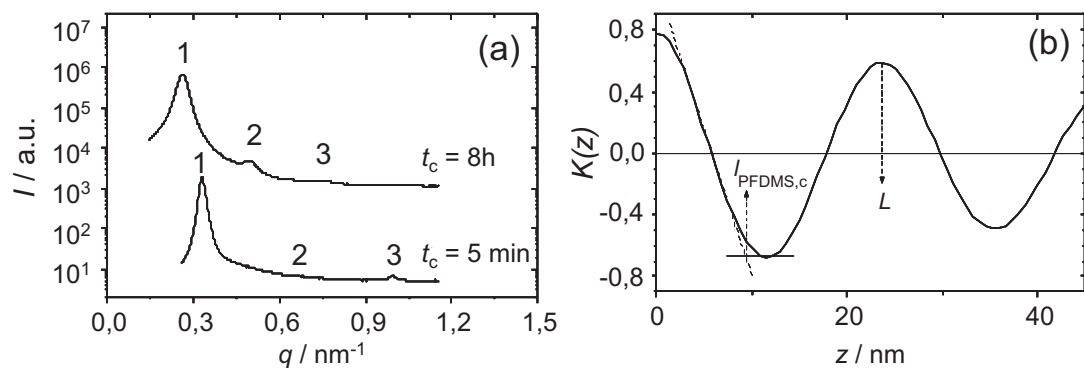

Figure 8. a) SAXS curves recorded at $120^{\circ} \mathrm{C}$ after $5 \mathrm{~min}$ (bottom curve) and $8 \mathrm{~h}$ (top curve) annealing at $120^{\circ} \mathrm{C}$, corresponding to lamella grains containing only fully non-crystalline and only fully crystallized PFDMS layers, respectively. b) 1D electron density correlation function $K(\mathrm{z})$ for the fully crystallized sample (after $8 \mathrm{~h}$ annealing at $120^{\circ} \mathrm{C}$ ). L: lamella long period; $I_{\text {PFDMS, }}$ : thickness of a crystallized PFDMS layer. optical microscopy, it was observed that crystallization of PEO in one layer induces PEO crystallization in the adjacent layers. ${ }^{[78]}$ Such a mechanism might also be in operation in the PS-b-PFDMS system. However, based on our detailed analysis of the development of the lamella structure upon PFDMS crystallization, we propose another transfer mechanism to be in operation.

As there is exactly one type of lamellae in the samples prior to and after full PFDMS crystallization, SAXS curves like those shown in Figure 8a can be analyzed reliably using the 1D correlation function $K(z),{ }^{[24]}$

$$
K(z)=\frac{1}{r_{e}^{2}(2 \pi)^{3}} \int_{0}^{\infty} \cos (q z) 4 \pi q^{2} I(q) \mathrm{d} q
$$

Figure $8 b$ yields an example of such a 1D electron density correlation function for a PS-b-PFDMS sample that was fully crystallized at $T_{\mathrm{C}}=120^{\circ} \mathrm{C}$. This allows calculation of the thickness of the PFDMS layers, $l_{\mathrm{PFDMS}, \mathrm{c}}$, and of the lamella long period, $L$. The value of $L$ can be determined as the location of the first maximum of $K(z)$, and that of $l_{\text {PFDMS, }}$ as the value of $z$ where the tangent at the first minimum of $K(z)$ intersects with the straight line through the first turning point of $K(z)$.

Figure 9a displays the plot of the long periods, $L$, calculated in this manner for the non-crystalline samples, as well as for the samples that were allowed to fully 

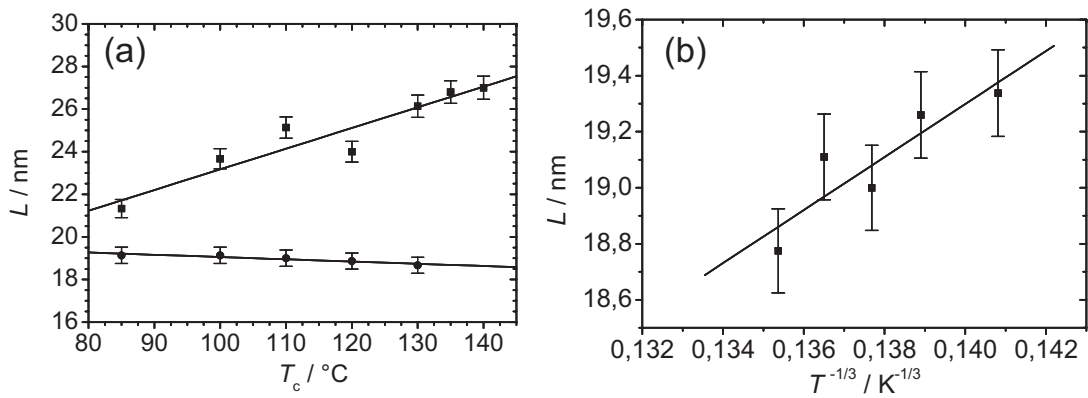

Figure 9. a) Lamella long periods, $L$, of the non-crystalline (O) and fully crystallized samples $(\boldsymbol{\square})$, as determined for different crystallization temperatures, $T_{\mathrm{c}}$. b) Plot of the long periods, $L$, of the amorphous block copolymer lamellae as a function of $T^{-1 / 3}$.

crystallize at different $T_{\mathrm{c}} \mathrm{s}$. One can see that $L$ decreases slightly with increasing $T_{\mathrm{c}}$ for the non-crystalline material, but increases clearly for the crystallized samples. Moreover, the lamella long periods for the non-crystalline material scale nicely with the temperature by a power law with exponent $-1 / 3$ (Figure $9 b) .{ }^{[16,17]}$ This demonstrates the effect of opposing factors in the free energy of the system. They refer to the preference for chain stretching in the crystalline layers and a coiled chain conformation in the amorphous layers.

The thicknesses of the PFDMS and PS layers, both prior to and after PFDMS crystallization, and for a broad range of crystallization temperatures, $T_{\mathrm{c}}$, are displayed in Figure 10a, b. The lamella long periods decrease slightly with increasing $T_{\mathrm{c}}$ for the non-crystalline case but increase considerably if the PFDMS is crystallized, where the increase grows slightly with $T_{\mathrm{c}}$. Therefore, a tremendous stretching of the whole grains perpendicular to their lamella planes must be the consequence of PFDMS crystallization. This stretching, however, is not only the result of increasing thicknesses of the PFDMS lamellae upon their transformation in the crystalline state. That could be expected because of increasing crystallite thicknesses with
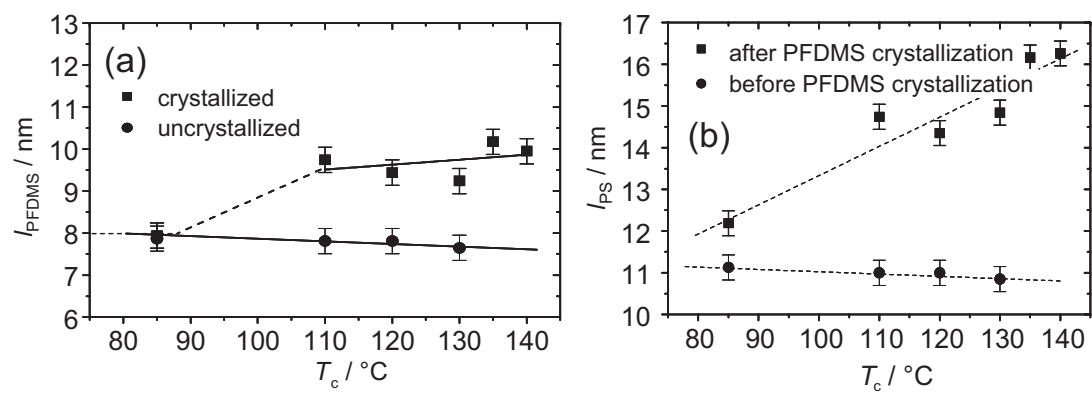

Figure 10. a) Thicknesses of the individual PFDMS layers, $I_{\text {PFDMS,a }}$ and $I_{\text {PFDMS }, c}$, for the uncrystallized and fully crystallized case, as determined for different crystallization temperatures, $T_{\mathrm{c}}$. b) Thicknesses of the individual PS layers, $I_{\mathrm{PS}, \mathrm{a}}$ and $I_{\mathrm{PS}, \mathrm{c}}$, for the cases of non-crystalline and fully crystallized PFDMS, determined at different $T_{c} s$. The dashed line sections in (a) indicate the unknown course of $I_{\text {PFDMS }}\left(T_{c}\right)$ at the glass transition. increasing $T_{\mathrm{c}}$, as is found for PFDMS homopolymers. ${ }^{[57]}$ In fact, the PS layer thicknesses increase to an even larger extent, as is shown in Figure 10b: at $T_{\mathrm{c}}=140^{\circ} \mathrm{C}$, for example, the thickness of the PFDMS layers increases by about 30\%, whereas that of the PS layer increases by about $50 \%$. At $T_{\mathrm{C}}=85^{\circ} \mathrm{C}$, moreover, there is no change in $l_{\text {PFDMS }}$ upon PFDMS crystallization but, nevertheless, there is still some increase in $l_{\mathrm{PS}}$. However, the temperature here is only slightly below $T_{\mathrm{g}}(\mathrm{PS})$, and there may already be a certain chain mobility. In addition, assuming a constant volume at the local level, the tremendous changes in the PS layer thicknesses are obviously caused by the expansion of the volume fraction of PS upon PFDMS crystallization since PFDMS has a higher density in the crystalline state, i.e., a smaller volume, than in the amorphous one.

The described structural features and the crystallization kinetics cannot be understood in the frame of the crystallization schemes discussed in the literature. They all lead to a homogeneous spread of crystallization throughout the whole material, and the crystallization rate is moderate. A reasonable explanation of the rapid expansion of PFDMS crystal growth perpendicular to the lamella planes, i.e., through the amorphous PS layers, is what we call 'squeezing transfer' (Figure 11): let us imagine a grain where PFDMS crystallization just starts in one single lamella (Figure 11a to b; 'seed layer'). In this first lamella, the PFDMS crystallite grows until depletion of the crystallizing material, and/or until the conversion process reaches the end of its individual lamella. Simultaneously with the crystallization within the seed lamella, the cross-sectional area per block junction decreases because of the increasing PFDMS density and layer thickness. Accordingly, the PS blocks connected to the crystallizing PFDMS chains will be squeezed into a coiled state, which is elongated in the lamella normal direction (Figure $11 \mathrm{~b}$ to c; squeezing is indicated by arrows): the PS and PFDMS blocks are bound together and thus their chain segments must, on average, have the same cross-section. Thus, increasing thickness of the amorphous PS lamella is the result of the lateral squeezing of the PS chains. As the PS segments are entangled in their domains, stretching of one PS segment will deform neighboring PS segments to some extent as well (Figure 11c to d). Therefore, finally, the still amorphous PFDMS coils residing in the neighboring lamella will also 'perceive' some mechanical stress and 


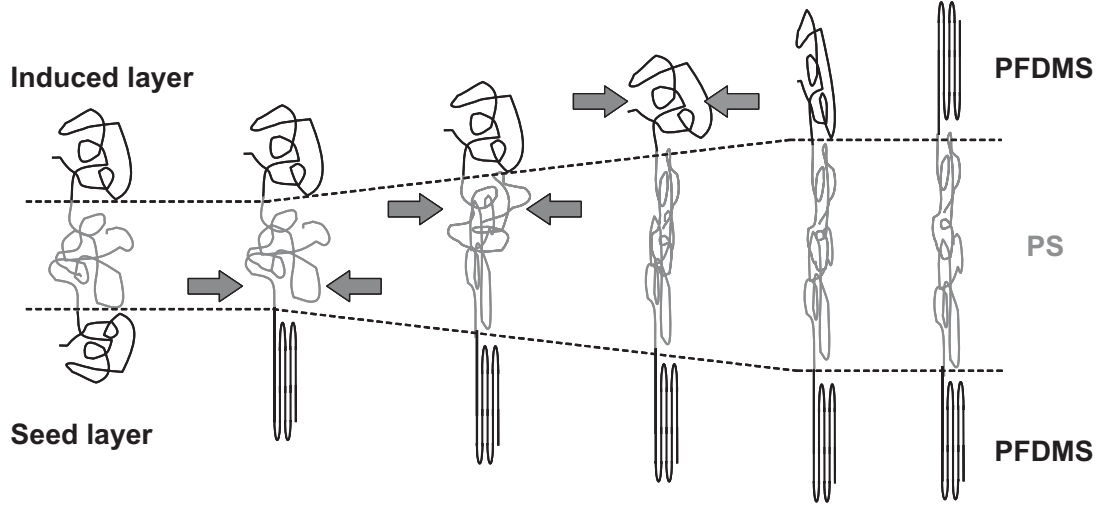

(a)

(b)

(c)

(d)

(e)

Figure 11. Snapshots of a section of a grain upon crystallization in one lamella. See text for details.
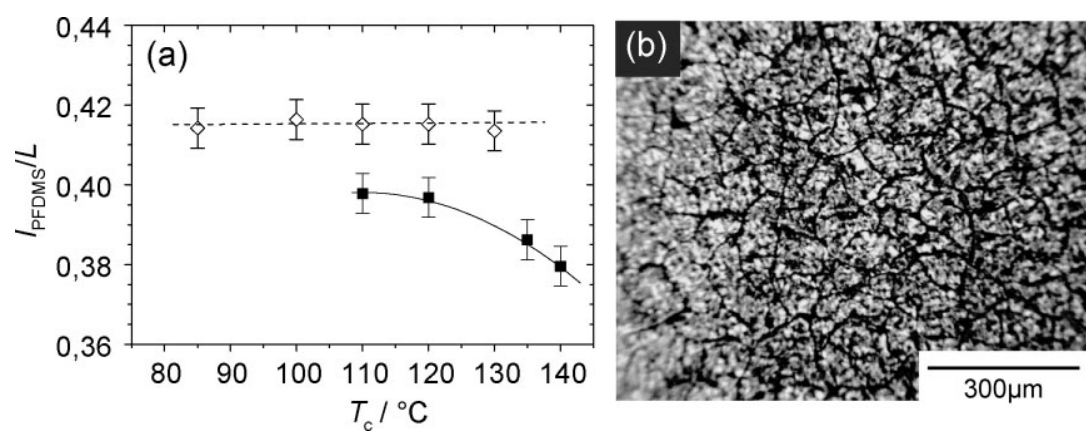

Figure 12. a) Plot of the ratio $I_{\text {PFDMS }} / L$ for different crystallization temperatures, $T_{\mathrm{c}}$, prior to $(\diamond)$ and after $(\boldsymbol{\square})$ crystallization. b) Polarization micrograph of a crystallized sample of a PS- $b$-PFDMS diblock copolymer showing many cracks that were not present in the originally amorphous film.

thus undergo some elongation perpendicular to the lamella plane (Figure 11d to e). The entropy of these squeezed PFDMS chains decreases, the effective undercooling increases, and their tendency to undergo the transformation into the low-entropy crystalline state increases accordingly. As such, squeezing of the PFDMS segments 'nucleates' PFDMS crystallization in the neighboring PFDMS lamella, the PFDMS chains crystallize much more rapidly (Figure 11e to f). In other words, squeezing tremendously increases the rate of nucleation, analogous to what is generally found for chains elongated in shear fields. ${ }^{[79]}$ This is why we call the process 'coupled crystallization'. The process will continue until the 'squeezing transfer' process stops at a barrier, maybe a change in the lamella orientation, which defines the grain boundary.

For coupled crystallization by squeezing transfer, the PS chains i) must be flexible enough, ii) must be structured to each other in a way that they ensure a sufficient transfer of forces and stresses, which can realized best by entanglements within their layers, and iii) the grains as a whole must be able to contract freely in the lamellae plane. Since $T_{c}$ (f)

was either around or slightly above $T_{\mathrm{g}}(\mathrm{PS})$ in all experiments, the PS chains can be assumed to be sufficiently mobile and entangled for such a mechanism. ${ }^{\mathrm{C}}$ In agreement with this assumption, the squeezing transfer rate was found to increase with decreasing crystallization temperature: below $125^{\circ} \mathrm{C}$, it is so fast that crystallization - if nucleated anywhere - spreads immediately over the whole grain. At higher temperatures, in contrast, the PS chain mobility is higher, the PS chain entanglement is less efficient, and hence the squeezing-transfer efficiency is lower. Consequently, intermediate states of only partially crystallized grains can be observed in the SAXS studies. Moreover, the remaining noncrystalline PFDMS layers residing in either fully amorphous or partially crystallized grains are increasingly stretched with an increase of the overall degree of PFDMS crystallinity in the sample. As a consequence, the long period increases gradually, and the associated distribution broadens progressively (Figure 7a, peak 1).

Without doubt, the spatial changes associated with PFDMS crystallization in the lamellar PS- $b$-PFDMS diblock copolymer induce stress states in the bulk material. The question is what mechanisms might lead to some relaxation. On the one hand, the accumulated stresses might induce macroscopic cracks in the material. Indeed, analysis of initially defect-free amorphous block copolymer films by polarization microscopy showed that, after PFDMS crystallization, the sample was crossed by many cracks (Figure 12b). Moreover, evidence was found that there is considerable perturbation within the crystalline PFDMS lamellae, especially in samples crystallized at relatively low $T_{\mathrm{C}} \mathrm{s}$ : let us recall that the volume fraction of PFDMS in the amorphous sample is 0.414 , but only 0.386 in the completely crystallized sample. Moreover, the ratio of the PFDMS layer thicknesses $l_{\text {PFDMS,a }}$ and $l_{\text {PFDMS }, \mathrm{c}}$ and the lamella long periods, $L$, must correspond to the volume fraction of the PFDMS in the respective sample. This is indeed exactly the case for the non-crystallized material at all investigated temperatures (Figure 12a). After crystal-

\footnotetext{
${ }^{c}$ The molecular weight of the PS blocks $(12 \mathrm{kDa})$ is around the critical entangling molar mass of $\mathrm{PS},{ }^{[80]}$ possibly rendering an effective entanglement between PS chains from the neighboring layers under the applied conditions.
} 
lization, however, the PFDMS densities - as estimated from the ratios of $l_{\text {PFDMS, }}$ and $L$-were clearly below the expected value for $T_{\mathrm{C}} \mathrm{S} \leq 125^{\circ} \mathrm{C}$. Micro-cracks and micro-cavities residing in the crystallized PFDMS lamellae might serve as an explanation. This assumption is supported by TEM pictures providing evidence of some inhomogeneities in the crystalline PFDMS layers (see Figure 5). Moreover, amorphous but clearly elongated PFDMS chain segments might survive the crystallization process - especially when it is carried out without self-seeding. In addition to PFDMS subphases that contain larger amounts of PS impurities, such elongated but amorphous PFDMS chains could explain the unexpectedly high glass transition temperature $T_{\mathrm{g}}$ (PFDMS) observed for partially crystallized PS-b-PFDMS diblock copolymers.

\section{Conclusion}

Isothermal crystallization of a lamellar PS- $b$-PFDMS diblock copolymer has been shown to proceed by grain-by-grain transformation of larger stacks of originally amorphous PFDMS lamellae into crystalline ones. Although PFDMS crystallization is usually very slow, here it was found to proceed surprisingly fast within the individual blockcopolymer grains. The in situ SAXS investigations were only able to resolve partially crystallized grains at very high temperatures. In all other cases, the SAXS patterns (time resolution less than $1 \mathrm{~s}$ ) represent the superposition of the scattering features of either fully amorphous or fully crystallized grains. We assume, therefore, that one single nucleation event is sufficient to induce immediate crystallization of the whole grain. Moreover, the high rate of crystal growth within a grain - in combination with the considerable spatial changes associated with PFDMS crystallization - lead to the conclusion that a highly efficient pathway must be accessible which allows spreading of the crystallization even perpendicular to the lamella planes, i.e., passing through the amorphous PS layers. We propose a 'squeezing transfer', and thus call the process 'coupled crystallization'. Further investigations on the bulk materials as well as on thin-film samples are currently in progress.

Acknowledgements: The authors thank the Deutsche Forschungsgemeinschaft (DFG), the Fonds der Chemischen Industrie (FCI), and the Dr. Otto Röhm Foundation for financial support of this work. Helpful discussions with Prof. G. Strobl (Freiburg University), and technical support provided by Dr. S. S. Funari (DESY, Hamburg) and Mrs. Y. Xu (DKI) for the X-ray measurements are gratefully acknowledged.

Received: April 26, 2010; Revised: July 23, 2010; Published online: September 28, 2010; DOI: 10.1002/macp.201000220
Keywords: block copolymers; crystallization; hybrid materials; poly(ferrocenyl dimethylsilane); morphology

[1] G. Strobl, Prog. Polym. Sci. 2006, 31, 398.

[2] Y.-S. Sun, T.-M. Chung, Y.-J. Li, R.-M. Ho, B.-T. Ko, U. S. Jeng, B. Lotz, Macromolecules 2006, 39, 5782.

[3] C. Vasilev, G. Reiter, S. Pispas, N. Hadjichristidis, Polymer 2006, 47, 330.

[4] J. K. Hobbs, R. A. Register, Macromolecules 2006, 39, 703.

[5] W. T. S. Huck, Chem. Commun. 2005, 33, 4143.

[6] P. Huang, L. Zhu, Y. Guo, O. Ge, A. J. Jing, W. Y. Chen, R. P. Quirk, S. Z. D. Cheng, E. L. Thomas, B. Lotz, B. S. Hsiao, C. A. Avila-Orta, I. Sics, Macromolecules 2004, 37, 3689.

[7] M. V. Massa, K. Dalnoki-Veress, Phys. Rev. Lett. 2004, 92, 255509.

[8] G. Reiter, J. Polym. Sci., B: Polym. Phys. 2003, 41, 1869.

[9] J.-T. Xu, J. P. A. Fairclough, S.-M. Mai, A. J. Ryan, C. Chaibundit, Macromolecules 2002, 35, 6937.

[10] J.-T. Xu, S. C. Turner, J. P. A. Fairclough, S.-M. Mai, A. J. Ryan, C. Chaibundit, C. Booth, Macromolecules 2002, 35, 3614.

[11] Y.-L. Loo, R. A. Register, A. J. Ryan, Macromolecules 2002, 35, 2365.

[12] A. J. Müller, V. Balsamo, M. L. Arnal, T. Jakob, H. Schmalz, V. Abetz, Macromolecules 2002, 35, 3048.

[13] L. Zhu, P. Huang, W. Y. Chen, O. Ge, R. P. Quirk, S. Z. D. Cheng, E. L. Thomas, B. Lotz, B. S. Hsiao, F. Yeh, L. Liu, Macromolecules 2002, 35, 3553.

[14] R. Opitz, D. M. Lambreva, W. H. de Jeu, Macromolecules 2002, 35, 6930

[15] J. M. Schultz, "Polymer Crystallization: The Development of Crystalline Order in Thermoplastic Polymers", Oxford University Press, Washington 2001.

[16] S. Hong, L. Yang, W. J. MacKnight, S. P. Gido, Macromolecules 2001, 34, 7009

[17] E. A. DiMarzio, C. M. Guttmann, J. D. Hoffman, Macromolecules 1980, 13, 1194.

[18] G. Reiter, G. Castelein, J.-U. Sommer, A. Röttele, T. ThurnAlbrecht, Phys. Rev. Lett. 2001, 87, 226101.

[19] L. Zhu, S. Z. D. Cheng, B. H. Calhoun, O. Ge, R. P. Quirk, E. L. Thomas, B. S. Hsiao, F. Yeh, B. Lotz, Polymer 2001, 42, 5829.

[20] Y.-L. Loo, R. A. Register, A. J. Ryan, G. T. Dee, Macromolecules 2001, 34, 8968.

[21] Y.-L. Loo, R. A. Register, Phys. Rev. Lett. 2000, 84, 4120.

[22] J. Bodycomb, D. Yamaguchi, T. Hashimoto, Macromolecules 2000, 33, 5187.

[23] I. W. Hamley, Adv. Polym. Sci. 1999, 148, 113.

[24] G. Strobl, "The Physics of Polymers: Concepts for Understanding their Structures and Behaviour", 2. ed., Springer, Berlin Heidelberg 1996.

[25] H. Frensch, P. Harnischfeger, B. J. Jungnickel, Multiphase Polymers: Blends and Ionomers, ACS Symposium Series 395, American Chemical Society, Washington DC, 1989, p. 101.

[26] I. W. Hamley, "The Physics of Block Copolymers", Oxford University Press, New York, 1998.

[27] A. J. Ryan, I. W. Hamley, W. Bras, F. S. Bates, Macromolecules 1995, 28, 3860

[28] D. A. Foucher, B.-Z. Tang, I. Manners, J. Am. Chem. Soc. 1992, 114, 6246.

[29] Y. Ni, R. Rulkens, I. Manners, J. Am. Chem. Soc. 1996, 118, 4102.

[30] R. G. H. Lammertink, M. A. Hempenius, I. Manners, G. Julius Vancso, Macromolecules 1998, 31, 795.

[31] R. G. H. Lammertink, M. A. Hempenius, E. L. Thomas, G. J. Vancso, J. Polym. Sci., Part B: Polym. Phys. 1999, 37, 1009. 
[32] R. G. H. Lammertink, M. A. Hempenius, G. J. Vancso, Langmuir 2000, 16, 6245.

[33] V. S. Papkov, M. V. Gerasimov, I. I. Dubovik, S. Sharma, V. V. Dementiev, K. H. Pannell, Macromolecules 2000, 33, 7107.

[34] D. Wöhrle, A. D. Pomogailo, "Metal Complexes and Metals in Macromolecules: Synthesis, Structure and Properties", WileyVCH, Weinheim 2003.

[35] C. E. Carraher, A. Abd-El-Aziz, C. Pittman, J. Sheats, M. Zeldin, "A Half Century of Metal and Metalloid Containing Polymers", Wiley, New York 2003.

[36] I. Manners, "Synthetic Metal-Containing Polymers", WileyVCH, Weinheim 2004.

[37] D. E. Herbert, U. F. J. Mayer, I. Manners, Angew. Chem., Int. Ed. 2007, 46, 5060.

[38] V. Bellas, M. Rehahn, Angew. Chem., Int. Ed. 2007, 46, 5082.

[39] A. S. Abd-El-Aziz,, I. Manners, Eds, "Frontiers in Transition Metal-Containing Polymers", Wiley-Interscience, Hoboken, New Jersey 2007.

[40] J. A. Massey, K. Temple, L. Cao, Y. Rharbi, J. Raez, M. A. Winnik, I. J. Manners, J. Am. Chem. Soc. 2000, 122, 11577.

[41] I. Manners, Science 2001, 294, 1664.

[42] J. Raez, I. Manners, M. A. J. Winnik, J. Am. Chem. Soc. 2002, 124, 10381.

[43] X. S. Wang, M. A. Winnik, I. Manners, Macromol. Rapid Commun. 2002, 23, 210.

[44] J. F. Gohy, B. G. G. Lohmeijer, A. Alexeev, X. S. Wang, I. Manners, M. A. Winnik, U. S. Schubert, Chem. Eur. J. 2004, 10, 4315.

[45] C. Kloninger, M. Rehahn, Macromolecules 2004, 37, 1720.

[46] C. Kloninger, M. Rehahn, Macromolecules 2004, 37, 8319.

[47] U. Datta, M. Rehahn, Macromol. Rapid Commun. 2004, 25 , 1615.

[48] C. Kloninger, D. Knecht, M. Rehahn, Polymer 2004, 45, 8323.

[49] X. Wang, M. A. Winnik, I. Manners, Macromolecules 2005, 38 , 1928.

[50] I. Korczagin, R. G. H. Lammertink, M. A. Hempenius, S. Golze, G. J. Vancso, Adv. Polym. Sci. 2006, 200, 91.

[51] C. Kloninger, M. Rehahn, Macromol. Chem. Phys. 2007, 28, 833.

[52] V. Bellas, M. Rehahn, Macromol. Rapid Commun. 2007, 28, 1415.

[53] G. R. Whittell, I. Manners, Adv. Mater. 2007, 19, 3439.

[54] V. Bellas, M. Rehahn, Macromol. Chem. Phys. 2009, 210, 320.

[55] J. D. Hoffman, J. J. Weeks, J. Res. Natl. Bur. Stand. 1962, 66A, 13.
[56] K. Yamada, M. Hikosaka, A. Toda, S. Yamazaki, K. Tagashira, Macromolecules 2003, 36, 4802.

[57] J. Xu, B. Jungnickel, B. Stühn, M. Rehahn, Macromol. Chem. Phys. 2010, 211, 1261.

[58] H. Zhou, G. L. Wilkes, Polymer 1997, 38, 5735.

[59] R. V. Castillo, A. Müller, J. Prog. Polym. Sci. 2009, 34, 516.

[60] Y. L. Loo, R. A. Register, "Crystallization within Block Copolymer Mesophases", in: Developments in Block Copolymer Science and Technology, I. W. Hamley, Ed., Wiley, New York 2004.

[61] A. J. Müller, V. Balsamo, M. L. Arnal, Adv. Polym. Sci. 2005, 190, 1.

[62] A. J. Müller, V. Balsamo, M. L. Arnal, "Crystallization in Block Copolymers with more than one Crystallizable Block" in: Lecture Notes in Physics: Progress in Understanding of Polymer Crystallization, G. Reiter, G. Strobl, Eds., Springer, Berlin 2007.

[63] B. Nandan, J.-Y. Hsu, H.-L. Chen, Polym. Rev. 2007, 46, 143.

[64] D. J. Blundell, A. Keller, A. J. Kovacs, J. Polym. Sci., Part B: Phys. Chem. 1966, 481.

[65] D. J. Blundell, A. Keller, J. Macromol. Sci. -Phys. B 1968, 2, 301.

[66] A. J. Kovacs, A. Gonthier, Kolloid Z. Z. Polym. 1972, 250, 530.

[67] B. Fillon, J. C. Wittmann, B. Lotz, A. Thierry, J. Polym. Sci., Part B: Polym. Phys. 1993, 31, 1383.

[68] G. Strobl, Eur. Phys. J. E 2000, 3, 165.

[69] A. J. Müller, M. L. Arnal, Prog. Polym. Sci. 2005, 30, 559.

[70] M. V. Massa, M. S. M. Lee, K. Dalnoki-Veress, J. Polym. Sci., Part B: Polym. Phys. 2005, 43, 3438.

[71] A. T. Lorenzo, M. L. Arnal, J. J. Sanchez, A. J. Müller, J. Polym. Sci., Part B: Polym. Phys. 2006, 44, 1738.

[72] A. Maus, E. Hempel, T. Thurn-Albrecht, K. Saalwächter, Eur. Phys. J. 2007, E23, 91

[73] J. Xu, Y. Ma, W. Hu, M. Rehahn, G. Reiter, Nat. Mater. 2009, 8 , 348.

[74] A. P. Hammersley, ESRF Internal Report ESRF98HAo1T 1998, FIT2D V9.129 Reference Manual V3.1.

[75] M. D. Whitmore, J. Noolandi, Macromolecules 1988, 21, 1482.

[76] H. B. Eitouni, N. P. Balsara, H. Hahn, J. A. Pople, M. A. Hempenius, Macromolecules 2002, 35, 7765.

[77] U. Wiesner, Macromol. Chem. Phys. 1997, 198, 3319.

[78] S. Hong, W. J. MacKnight, T. P. Russell, S. P. Gido, Macromolecules 2001, 34, 2876.

[79] L. Li, W. H. de Jeu, Adv. Polym. Sci. 2005, 181, 75.

[80] L. J. Fetters, D. J. Lohse, D. Richter, T. A. Witten, A. Zirkelt, Macromolecules 1994, 27, 4639. 